\title{
A morphologically distinct Phlebotomus argentipes population from active cutaneous leishmaniasis foci in central Sri Lanka
}

\author{
Shalindra Ranasinghe ${ }^{1 /}{ }^{+}$, Rhaiza DC Maingon ${ }^{2}$, Daniel P Bray ${ }^{2}$, Richard D Ward ${ }^{2}$, \\ Chandani Udagedara $^{3,4}$, Manel Dissanayake ${ }^{4}$, Vathsala Jayasuriya ${ }^{5}$, Nissanka K de Silva ${ }^{6}$ \\ ${ }^{1}$ Department of Parasitology ${ }^{5}$ Department of Community Medicine, Faculty of Medical Sciences ${ }^{6}$ Department of Zoology, \\ Faculty of Applied Science, University of Sri Jayewardenepura, Gangodawila, Nugegoda, Sri Lanka \\ ${ }^{2}$ Centre for Applied Entomology and Parasitology, Institute for Science \& Technology in Medicine, Keele University, Staffordshire, UK \\ ${ }^{3}$ Dermatology Unit, Matale Base Hospital, Matale, Sri Lanka ${ }^{4}$ Dermatology Unit, Teaching Hospital Kandy, Kandy, Sri Lanka
}

\begin{abstract}
Although the reported aetiological agent of cutaneous leishmaniasis (CL) in Sri Lanka is Leishmania donovani, the sandfly vector remains unknown. Ninety-five sandflies, 60 females and 35 males, collected in six localities in the district of Matale, central Sri Lanka, close to current active transmission foci of CL were examined for taxonomically relevant characteristics. Eleven diagnostic morphological characters for female sandflies were compared with measurements described for Indian and Sri Lankan sandflies, including the now recognised Phlebotomus argentipes sensu lato species complex. The mean morphometric measurements of collected female sandflies differed significantly from published values for $\mathrm{P}$. argentipes morphospecies B, now re-identified as Phlebotomus annandalei from Delft Island and northern Sri Lanka, from recently re-identified P. argentipes s.s. sibling species and from Phlebotomus glaucus. Furthermore, analysis of underlying variation in the morphometric data through principal component analysis also illustrated differences between the population described herein and previously recognised members of the P. argentipes species complex. Collectively, these results suggest that a morphologically distinct population, perhaps most closely related to P. glaucus of the P. argentipes s.l. species complex, exists in areas of active CL transmission. Thus, research is required to determine the ability of this population of flies to transmit cutaneous leishmaniasis.
\end{abstract}

Key words: cutaneous leishmaniasis - distinct Phlebotomus argentipes population - putative vector - Sri Lanka

Sandflies transmit protozoan Leishmania parasites that cause the leishmaniasis, a set of neglected diseases with half a million new cases and approximately 60,000 deaths per annum and much morbidity disproportionally affecting the poorest of the world population (WHO 2010). Targeted sandfly vector control is among a number of intervention measures deemed important for controlling these diseases (Murray et al. 2005). In Sri Lanka, an island with a total square area of $65,610 \mathrm{~km}^{2}$ situ-

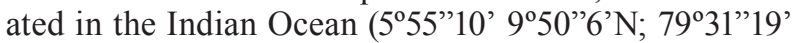
$\left.81^{\circ} 52^{\prime \prime} 36^{\prime} \mathrm{E}\right)$, cutaneous, visceral and mucosal leishmaniasis have been described, with an increasing number of cutaneous (CL) cases being reported $(>2,000$ cases in the last 8 years) in the north central, northeastern, central and southern regions (Athukorale et al. 1992, Rajapaksa et al. 2005, Abeygunasekara et al. 2007, Nawaratna et al. 2007, Karunaweera \& Rajapaksa 2009, Karunaweera 2009, Siriwardana et al. 2010, MHNSL 2010). Unusually, the only strain isolated to date from skin lesions is Leishmania donovani Laveran \& Mesnil MON-37, a zymodeme differing by only one nucleotide substitution

Financial support: University of Sri Jayewardenepura (ASP/06/ $\mathrm{RE} / 2008 / 03$ )

DPB is supported by a grant from the Welcome Trust.

+ Corresponding author: ishalindra@yahoo.com

Received 22 July 2011

Accepted 2 December 2011 in the glucose-6-phosphate dehydrogenase gene from $L$. donovani MON-2, the strain most commonly isolated from visceral leishmaniasis (VL) cases in India (Karunaweera et al. 2003, Nawaratna et al. 2007, Siriwardana et al. 2007). Furthermore, CL-derived Sri Lankan donovani isolates comprise a separate cluster more closely related to L. donovani isolates from India, Nepal and Bangladesh than to African parasites in phylogenetic analyses using microsatellite markers (Siriwardana et al. 2007). Dermotropic L. donovani isolates from Sri Lanka and other regions, including Sudan and India, suggest a role(s) for host immunogenetics, zoonotic transmission and/or differential Leishmania transmission by specific sandfly vectors (Elamin et al. 2008, Samaranayake et al. 2008, Nawaratna et al. 2009, Rosypal et al. 2010).

The vector of leishmaniasis in Sri Lanka has yet to be identified. It is thought that Phlebotomus argentipes Annandale and Brunetti (Diptera: Psychodidae), the major vector of VL (kala-azar) in India, is the predominant sandfly species also in Sri Lanka (Carter \& Antonipulle 1949, Lewis \& Killick-Kendrick 1973, Lane et al. 1990, Surendran et al. 2005, 2007, Ozbel et al. 2011). Phlebotomus stantoni, a species that is not a suspected vector, was only found in the southern forested districts and at least eight species of Sergentomyia were reported by Ozbel et al. (2011).

A taxonomic reassessment by Ilango (2010) indicated at least three sibling species within the P. argentipes s.l. species complex in India: $P$. argentipes Annandale and Brunetti s.s., Phlebotomus annandalei Sinton and Phlebotomus glaucus Mitra \& Roy. P. argentipes s.s., the 
known vector for VL in India, was found in sympatry with $P$. glaucus, although the latter has not been reported to act as a vector of VL and $P$. annandalei was mainly found in areas that are non-endemic for VL in India, including the Tamil Nadu area in southern India(Ilango et al. 1994, Ilango 2010).

There has been relatively little published research on the taxonomy, geographical distribution, prevalence and biology of sandflies in Sri Lanka. The female sandfly of $P$. argentipes from Sri Lanka was morphologically described 30 years ago (Lewis 1978). More recently, a study showed the existence of $P$. argentipes morphospecies B (Surendran et al. 2005) on Delft Island $\left(9^{\circ} 28^{\prime \prime} 9^{\circ} 34^{\prime \prime N}\right.$, $79^{\circ} 37^{\prime \prime} 79^{\circ} 48^{\prime \prime} \mathrm{E}, 35 \mathrm{~km}$ from the northwestern coast of mainland Sri Lanka and $37 \mathrm{~km}$ from south India). This morphospecies was re-described as $P$. annandalei by Ilango (2010) and characterised as a "short ascoid form" based on the ratio between the length of the sensilla chaeticum, e.g., the ascoid (Lewis \& Killick-Kendrick 1973, Ilango et al. 1994, 2000, Lane \& Rahman 1980) on antennal flagellomere A2 and the length of flagellomere A2 $<0.5(n=41)$. For $P$. argentipes morphospecies A, a "long ascoid form" that was re-assessed by the same author (Ilango 2010) and determined to be P. glaucus, the ratio described above is $>0.5$ and this morphospecies was caught in the Pelawatta area $(n=4)$ in the district of Moneragala of mainland southeastern Sri Lanka. However, the sandfly collection from Delft Island was not from habitats in which CL cases had been reported and the sandfly numbers from these studies were small (Surendran et al. 2005, Ilango 2010). Recently, evidence of the presence of the three $P$. argentipes s.l. sibling species in a northern Sri Lanka area where three CL cases were recorded in 2010 was reported (Gajapathy et al. 2011).

The present study describes, for the first time, the main morphological characteristics of 95 sandflies collected at currently active transmission foci of CL in central Sri Lanka and compares these flies to those described previously as $P$. annandalei, $P$. argentipes and $P$. glaucus. In addition, principal component analysis (PCA) illustrates the underlying differences between the morphological data described herein and those data previously reported for other members of the $P$. argentipes species complex.

\section{SUBJECTS, MATERIALS AND METHODS}

Study area - The district of Matale, in central Sri Lanka, the study location for this study, is a recognised endemic region contributing 10-21 new CL cases per annum (Nawaratna et al. 2009) with 10 patients reported between January 2009-September 2009 (MHNSL 2009). Nine locations were selected for sandfly collections, all situated within 2-22 km of each other in the central Matale, in which 16 patients with CL have been reported at the Matale and Kandy Dermatology Clinics (Supplementary data). The geographical locations ranged from $7^{\circ} 27^{\prime} 34^{\prime \prime} 7^{\circ} 49^{\prime} 50^{\prime \prime}$ north and $80^{\circ} 30^{\prime} 80^{\circ} 42^{\prime} 25^{\prime \prime}$ east. This area is semi-dry with an annual average rainfall of 1879.4 $\mathrm{mm}$, mainly from the northeast monsoon from OctoberJanuary and is $220-340 \mathrm{~m}$ above sea level. Fifty percent of the reported $16 \mathrm{CL}$ cases in this area were from Bibila and Arangala, two geographically close communities (Supplementary data, Table I).

Patient information was obtained from the "Patient Information Register" maintained at the Dermatology Clinics in two hospitals (Base Hospital Matale and the Teaching Hospital Kandy), the closest dermatology clinics for patients living in Matale. Diagnosis was by microscopic detection of Leishmania amastigotes in Giemsa skin smears, histology or the detection of promastigotes in in vitro cultures derived from punch biopsy samples carried out by the medical staff in these hospitals. There were 16 positively diagnosed patients who had either been treated or were receiving treatment.

Collection of sandflies - Sandflies were collected using a WHO-recommended $10 \mathrm{ft}$ x $10 \mathrm{ft}$ cattle-baited trap (WHO 1992) set between $06.00 \mathrm{pm}-10.00 \mathrm{pm}$ within $50 \mathrm{~m}$ of houses where positive cases of leishmaniasis had

TABLE I

Summary of patients reported from different locations in the district of Matale and number of identified sandflies from each location

\begin{tabular}{|c|c|c|c|c|c|}
\hline \multirow[b]{2}{*}{ Study area } & \multirow{2}{*}{$\begin{array}{l}\text { Positive cases } \\
\text { recorded at clinics } \\
\text { (n) }\end{array}$} & \multirow{2}{*}{$\begin{array}{l}\text { Patients on } \\
\text { recent }^{a} \text { treatment } \\
\text { (n) }\end{array}$} & \multirow{2}{*}{$\begin{array}{l}\text { Patients with } \\
\text { healed treated } \\
\text { lesions }{ }^{b} \\
\text { (n) }\end{array}$} & \multicolumn{2}{|c|}{$\begin{array}{l}\text { Sandflies identified at the species level } \\
\text { (n) }\end{array}$} \\
\hline & & & & Females & Males \\
\hline Bibila & 3 & 0 & 3 & 12 & 8 \\
\hline Nikula & 1 & 0 & 1 & 9 & 3 \\
\hline Wahakotte & 1 & 0 & 1 & 9 & 3 \\
\hline Lenadora & 1 & 1 & 0 & 7 & 6 \\
\hline Mahawela & 1 & 1 & 0 & 0 & 0 \\
\hline Malepitiya & 1 & 0 & 1 & 0 & 0 \\
\hline Arangala & 5 & 1 & 4 & 14 & 5 \\
\hline Ambana & 1 & 1 & 0 & 0 & 6 \\
\hline Palapathwela & 2 & 1 & 1 & 9 & 4 \\
\hline Total & 16 & 5 & 11 & 60 & 35 \\
\hline
\end{tabular}

$a$ : recent treatment was considered as treatment received within last six months; $b$ : patients who have taken treatment $>$ six months ago. 
been reported. Collected sandflies were stored in $70 \%$ $\mathrm{v} / \mathrm{v}$ ethanol (made using Ethanol Analytical ${ }^{\circledR} 99.7-100 \%$ $\mathrm{v} / \mathrm{v}, \mathrm{BDH}$ Laboratories).

Sandfly identification - Ninety-six sandflies (females $n=61$ and males $n=35$ ) from seven localities were identified to the genus and species level. The remaining unidentified sandflies were stored in $70 \% \mathrm{v} / \mathrm{v}$ ethanol for future studies.

Sandflies were treated overnight with $0.5 \% \mathrm{w} / \mathrm{v}$ $\mathrm{KOH}$ at room temperature as described previously (Ilango 2000) and subsequently mounted in Berlese's solution. Sandfly morphometric measurements, including the lengths of the eye, head, labrum, antennal flagellomeres 1-3 (A1, A2, A3), s. chaeticum on A2 and pharynx, the depth of pharyngeal armature, the wing width and wing vein branching (alpha, beta, gamma, delta, theta and epsilon) were made. The maxillary dental depth and the numbers of ventral and lateral-maxillary teeth were also recorded. The gonocoxite and gonostyle lengths were measured in males. All measurements were made with a calibrated eye-piece in an Olympus CH 30 light microscope (Olympus Optical Co Ltd, Japan) as described by El-Hossary (2006). Previously described and recently published taxonomic keys, morphometric measurements and figures were used to identify sandflies and to compare measurements (Lewis 1978, Surendran et al. 2005, Ilango 2010). Images were captured using an Olympus BX 50 light microscope with a Microscope Image Projection System (Magnus Analytics Model MIPS-USB, India).

The mean values of the morphometric characteristics reported herein were compared with those published previously (Surendran et al. 2005, Ilango 2010, Gajapathy et al. 2011) using two-tailed Student's $t$ tests. The mean values for sandflies described herein were also compared with those values reported by Lewis (1978) using onesample $t$ tests. In addition, the wing venation of 20 study sandflies, 10 males and 10 females, was examined to determine the fork position of the upper branch of the 2nd longitudinal vein (R2 + R3 junction). This vein forked before the tip of the 1st vein (R1) in the single female specimen of Phlebotomus marginatus reported by Brunetti (1912), instead of approximately below the tip as in $P$. argentipes s.l. Seven out of the 10 females and only five out of the 10 males examined in this study displayed a $P$. marginatus vein pattern, suggesting that perhaps this characteristic is an unreliable one for differentiating specimens of different species.

$P C A$ - PCA is a data reduction technique that is commonly applied to reveal underlying patterns in sets of complex data (Tabchnick \& Fidel 2001). In entomology, PCA has been used to facilitate the interpretation of morphological data by reducing sets of numerous measurements down to a few underlying components (Daly 1985). Component scores calculated for individuals can then be plotted and compared to visualise the extent to which populations differ overall, without the need to compare the populations across each individual morphological variable. This technique has recently been applied to the study of Phlebotomus spp taxonomy across India and Sri Lanka, with the results supporting the existence of a species complex (Ilango 2010).

Here, PCA was used to determine whether sandflies collected from Matale in this study could be separated from $P$. argentipes s.s., $P$. annandalei and $P$. glaucus based on variations in morphological characteristics. Eleven characteristics were chosen based on previous reports of diagnostic morphology for $P$. argentipes sibling species (Lewis 1978, Ilango 2000, 2010). These characteristics comprised the wing length, the wing index (R2/ $\mathrm{R} 2+3$ ), the wing R1 overlap/R2, the length of the A1 antennal flagellomere, the A1/A2 + A3 ratio, s. chaeticum/ A2, the labrum length, the number of maxillary lateral teeth, the number of maxillary ventral teeth, the maxillary dental depth and the ratio between the depth of the pharyngeal armature and the length of the pharynx. Reported data for $P$. argentipes s.s. $(\mathrm{n}=9), P$. annandalei $(\mathrm{n}=10)$ and P. glaucus $(\mathrm{n}=10)($ Ilango 2010) and for 60 female sandflies for which all data were available from the current study were entered into the PCA via the factor analysis procedure in PASW Statistics 18 (IBM Corporation). Resulting components with eigenvalues $>1$ were deemed statistically significant (Tabachnick \& Fidel 2001). The components were then rotated using the Varimax method to facilitate the interpretation of how the extracted components are related to morphometric characteristics (Tabachnick \& Fidel 2001).

To illustrate the extent to which flies from the current study could be separated from $P$. argentipes s.s., $P$. annandalei and $P$. glaucus, regression scores for each fly were first calculated for the first two extracted components, explaining the greatest proportion of variance in the original data. These scores were then plotted against each other (Tabacknick \& Fidel 2001). Scores for components 3 and 4 were similarly plotted against one another but failed to prove effective in the differentiation of siblings.

Ethics - Ethical approval was granted by the Ethical Review Committee, Faculty of Medical Sciences, University of Sri Jayewardenepura, Sri Lanka on 6 May 2010.

\section{RESULTS}

Sandfly taxonomy - A total of 1,008 sandflies were collected in cattle-baited traps within Matale with three times more males caught than females (males $=775$, females $=233$ ). With the exception of one female sandfly collected at Palapathwela, which was identified as Sergentomyia $\mathrm{sp}$., the remaining sandflies were identified as $P$. argentipes s.l. Ninety-five sandflies from Matale sandfly collection were subjected to further taxonomic analysis (Table I). Twenty-six out of sixty female specimens $(43.3 \%)$ were from two localities of Matale (Arangala and Bibila) (Supplementary data). All sixty female specimens were identified as $P$. argentipes s.l. based on spermatheca morphology (Fig. 1, Panel E). The mean values of 11 morphological characteristics for the 95 sandflies in the study sample did not match any previously described sibling of the $P$. argentipes species complex completely (Ilango 2010) (Figs 1, 2, Table II). 
The female sandflies of the study population - The female sandflies described herein had brown bodies and tarsi and differed significantly with respect to six (55\%), eight $(73 \%)$ or five $(45 \%)$ out of 11 morphometric characteristics reported for $P$. argentipes s.s., $P$. annandalei and $P$. glaucus, respectively. However, they differed significantly by only three out of $11(33 \%)$ morphometric measurements described 30 years earlier for a sandfly population of Sri Lankan origin (Table II). The mean morphometric values show the greatest differences with $P$. annandalei, $P$. argentipes (in both body and head parts) and P. glaucus (only in mouth parts and antenna) and the least difference with sandflies of Sri Lankan origin described 30 years ago (Lewis 1978). Prominent "diagnostic" characteristics include the ascoid length (s. chaeticum/A2 ratio), the number and shape of ventral teeth (dental depth) and the thickness of the pharyngeal armature (pharyngeal armature depth/pharynx length). The ratio between the length of the s. chaeticum on A2 and the length of A2 $(\sim 0.75)$ exclude the collected sandflies from the $P$. argentipes s.s. sibling species $(\sim 0.47)$, i.e., the known vector of VL in India and from the $P$. argentipes morphospecies B ( 0.42) identified from Delft Island (Lewis 1978) and re-described as P. annandalei (Ilango 2010) (Fig. 1, Panel B, Table II). The ratio between the s. chaeticum on A2 and the A2 length in the sandflies described herein $(\sim 0.75)$ is significantly higher than that of P. glaucus ( 0.69) (Ilango 2010) (Fig. 1, Panel
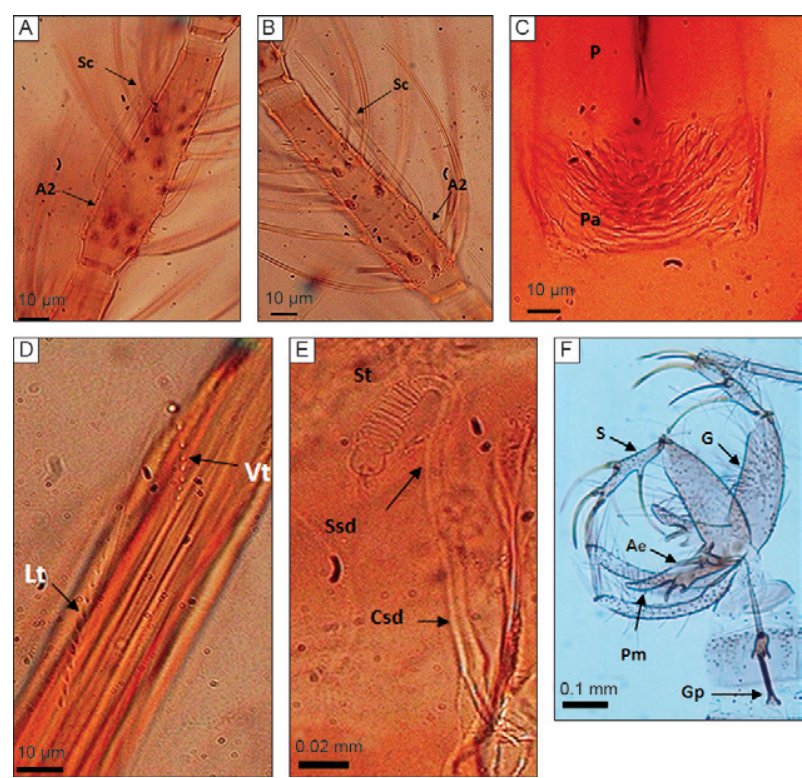

Fig. 1: light microscope images of antennal flagellomeres, mouthparts and genitalia of male and female sandflies collected in the district of Matale, central Sri Lanka \{A: male flagellomere II [antennal flagellomere 2 (A2)]; B: female flagellomere II (A2); C: female pharynx (P); D: female maxillary teeth; E: spermatheca with enlarged terminal segment; F: male genitalia and terminal segments\}. Ae: aedeagus; Csd: common spermathecal duct; G: gonocoxite; Gp: genital pump; Lt: lateral maxillary teeth; Pa: pharyngeal armature; PM: paramere; S: gonostyle; Sc: sensilla chaeticum; Ssd: single spermathecal duct; St: spermatheca; Vt: ventral maxillary teeth.
B, Table II). The needle-like morphology of the maxillary ventral teeth is similar to that of P. glaucus and is in contrast to the "brick" and "pyramidal" shapes of the teeth of $P$. argentipes s.s. and $P$. annandalei, respectively (Ilango 2010), (Fig. 1, Panel D), but the number of ventral teeth is significantly smaller in the collected samples than in $P$. glaucus. Finally, the pharyngeal armature of the study samples is shallower in depth than that of $P$. glaucus and those of the other two siblings (Ilango 2010) (Fig. 1, Panel C). This difference is confirmed by the ratio between the depth of the pharyngeal armature and the pharyngeal length, which, in the proposed new sibling species, is significantly smaller than that of all three previously reported argentipes sibling species (Table II).

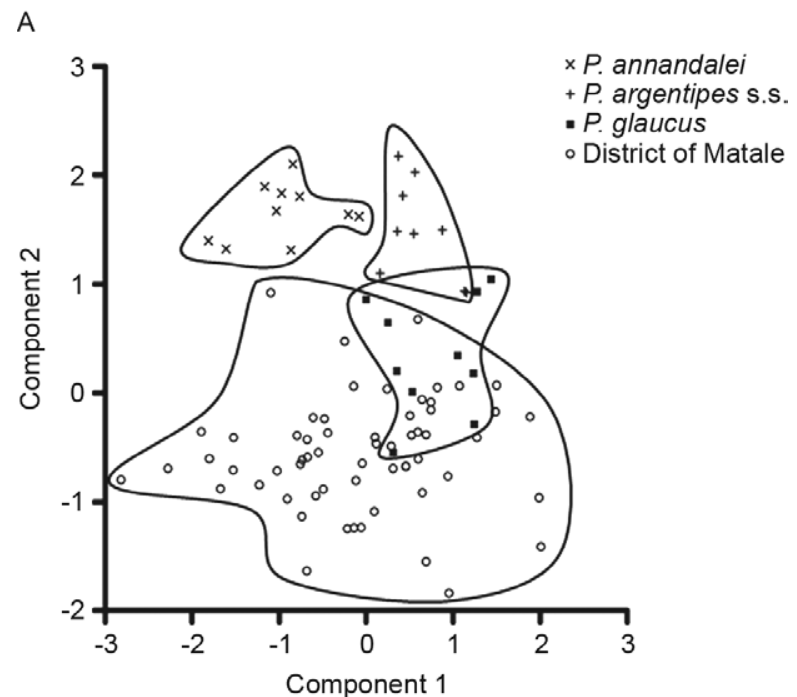

B

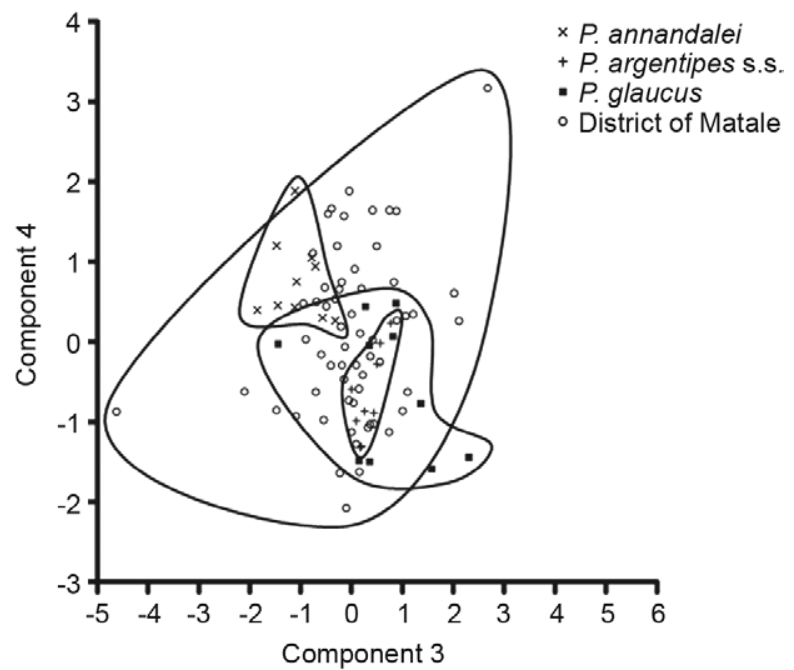

Fig. 2: principle component analysis regression scores for Phlebotomus annandalei $(\mathrm{n}=10)$ (Ilango 2010), Phlebotomus argentipes s.s. $(\mathrm{n}=9)$ (Ilango 2010), Phlebotomus glaucus $(\mathrm{n}=10)$ (Ilango 2010) and study sandfly population $(\mathrm{n}=60)$ (districti of Matale). A: scores for Varimax-rotated components 1 and 2; B: scores for Varimax-rotated components 3 and 4 . 


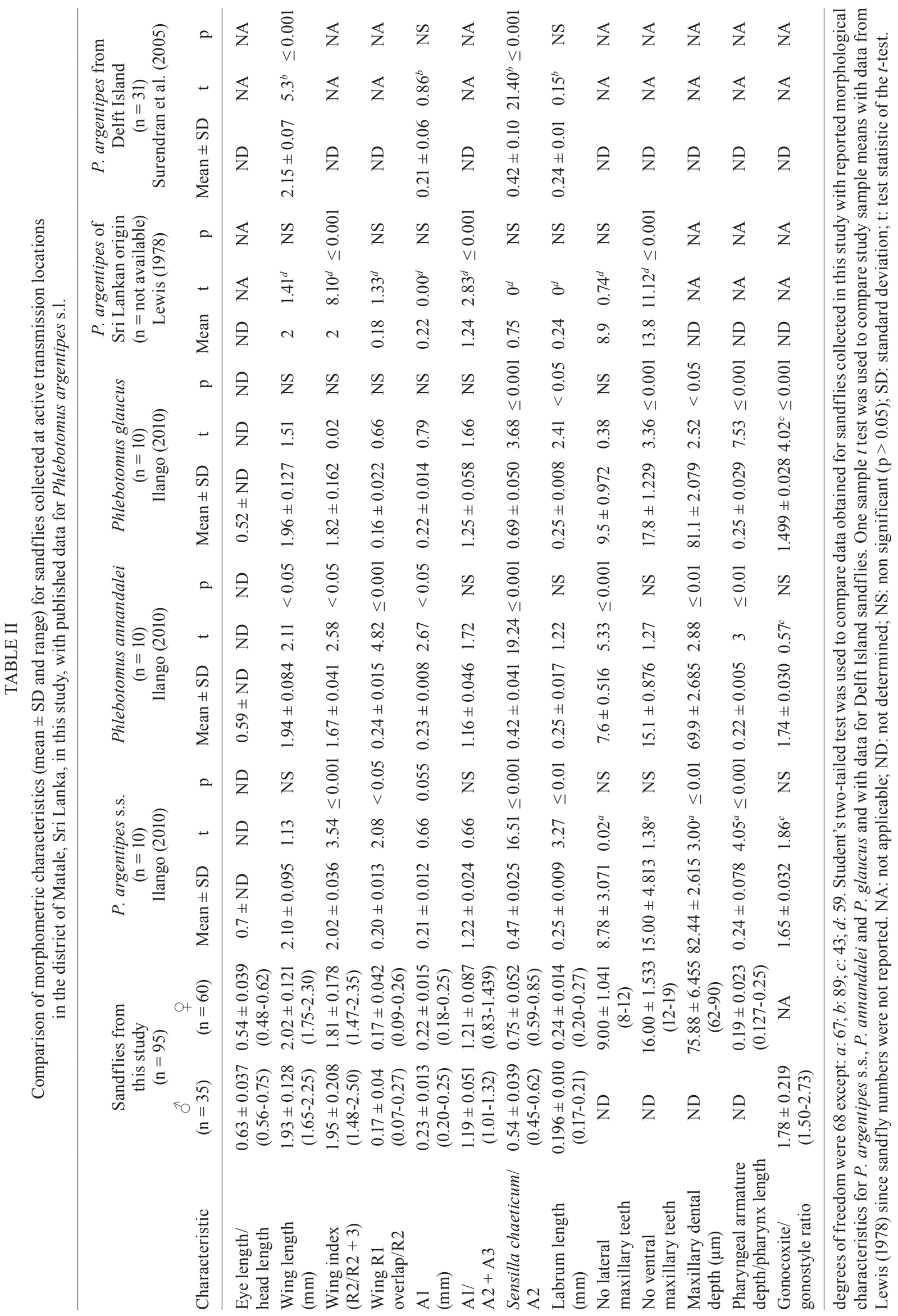


The male sandflies of the study population - Morphometric data for 35 male sandflies collected at Matale locations are shown in Table II. The ratio between the s. chaeticum on antennal flagellomere II (A2) and the length of the segment was $\geq 0.5$ in 33 out of 35 males (Fig. 1, Panel A, Table II). The ratio between gonocoxite and gonostyle was $>1.5$ in all the male sandflies. The mean value of this gonocoxite-to-gonostyle ratio was significantly higher than that of $P$. glaucus and there was no significant difference relative to the ratios of $P$. argentipes s.s. and $P$. annandalei, as described by Ilango (2010) (Fig. 1, Panel F, Table II).

The Matale study population showed significant differences in five out of six morphometric characteristics that were also measured for sandflies from Jaffna, northern Sri Lanka (Gajapathy et al. 2011): male eye length/ head length [test statistic of the $t$-test $(\mathrm{t})=2.96$, degrees of freedom (df) $=50, \mathrm{p} \leq 0.01$, male wing index)] (R2/ $\mathrm{R} 2+\mathrm{R} 3)(\mathrm{t}=2.27, \mathrm{df}=50, \mathrm{p} \leq 0.05)$, female wing $\mathrm{R} 1$ overlap/R2 $(\mathrm{t}=3.13, \mathrm{df}=85, \mathrm{p} \leq 0.01)$, s. chaeticum $/ \mathrm{A} 2$ (male: $\mathrm{t}=2.85, \mathrm{df}=50, \mathrm{p} \leq 0.01$; female: $\mathrm{t}=11.86, \mathrm{df}=$ $85, \mathrm{p} \leq 0.001)$ and gonocoxite/gonostyle $(\mathrm{t}=6.5, \mathrm{df}=50$, $\mathrm{p} \leq 0.001)$. In addition, the reported means for the wing length and the labrum length from the Jaffna study (data not shown) (Gajapathy et al. 2011) lie outside the 95\% confidence interval for the Matale study flies.

$P C A$ - Four components with eigenvalues greater than $1(2.71,1.98,1.39,1.11)$ were extracted from among 11 characteristics using PCA. Together, the four components explained $65.4 \%$ of the original variance within the included morphometric measurements. Varimax rotation resulted in four components with eigenvalues of $2.31,2.08,1.44$ and 1.36 , explaining $21 \%, 18.9 \%, 13.1 \%$ and $12.4 \%$ of the original variance, respectively. The first rotated component (Table III) included a strong positive loading for dental depth and component 2 had a strong negative loading for $s$. chaeticum/A2. Component 3 included a high positive loading for A1/A2 + A3 and component 4 was characterised by a strong positive loading for antennal flagellomere length (A1).

Plotting the first two rotated components against one another resulted in separate clusters for $P$. annandalei, $P$. argentipes and flies collected from Matale (Fig. 2, Panel A). $P$. annandalei and $P$. argentipes were separated from one another by differing values for component 1 , with both sibling species separated from flies collected from Matale by component 2. P. glaucus also formed a distinct cluster, overlapping with flies from Matale and to a lesser extent with $P$. argentipes. Plotting values for components 3 and 4 similarly produced clusters for each population/sibling species, but did not separate flies from Matale from $P$. annandalei, $P$. argentipes or P. glaucus (Fig. 2, Panel B).

\section{DISCUSSION}

We applied a comparative morphological approach to the identification of the $P$. argentipes sibling species collected at sites within active CL transmission foci in Sri Lanka, where CL is a newly established endemic disease and the vector is unknown.

The central Sri Lankan district of Matale, our study area, has previously been recognised as a CL-endemic area (Karunaweera 2009) and was included in a recent study on possible reservoir animals of Leishmania (Nawaratna et al. 2009). Six of these selected nine active CL locations are geographically clustered within an approximately $22 \mathrm{~km}$ region in the north of the study area, where $75 \%$ (12 out of 16) of the clinically diagnosed CL cases were reported in 2008 (MHNSL 2009). Fifteen of the 16 diagnosed, randomly selected patients in this study had no history of travel outside their residences to

TABLE III

Component loadings for four Varimax-rotated components extracted from 11 morphological characteristics of Phlebotomus annandalei $^{a}$, Phlebotomus argentipes s.s. ${ }^{b}$, Phlebotomus glaucus ${ }^{c}$ and study sandfly population ${ }^{d}$

\begin{tabular}{lcccc}
\hline & \multicolumn{3}{c}{ Component } \\
\cline { 2 - 4 } Character & 1 & 2 & 3 & 4 \\
\hline Wing length & 0.700 & -0.098 & -0.085 & 0.362 \\
Wing index (R2/R2 + R3) & 0.253 & 0.143 & 0.639 & -0.253 \\
Wing R1 overlap/R2 & -0.090 & 0.627 & 0.155 & 0.329 \\
Antennal flagellomere A1 & 0.272 & 0.198 & -0.002 & 0.852 \\
Ratio of A1/A2+ A3 & -0.064 & 0.021 & 0.790 & -0.357 \\
Sensilla chaeticum/A2 & 0.062 & -0.892 & 0.144 & 0.221 \\
Labrum length & 0.696 & 0.347 & -0.126 & -0.206 \\
No maxillary lateral teeth & -0.014 & -0.450 & 0.467 & -0.052 \\
No maxillary ventral teeth & 0.625 & -0.171 & 0.257 & -0.048 \\
Maxillary dental depth & 0.844 & 0.068 & 0.104 & -0.314 \\
Pharyngeal armature depth/length & 0.278 & 0.683 & 0.208 & \\
\hline
\end{tabular}

$a: \mathrm{n}=10$ (Ilango 2010); $b: \mathrm{n}=9$ (Ilango 2010); $c: \mathrm{n}=10$ (Ilango 2010); $d:(\mathrm{n}=60)$ (district of Matale). 
any other endemic area in the country during the period immediately before developing the disease. Therefore, it is possible that the sandfly vector is living in the neighbourhood of the patients' dwellings.

Three autochthonous cases of VL have been reported from the northern Sri Lanka districts (Abeygunasekara et al. 2007, Karunaweera \& Rajapaksa 2009). Both the causative Leishmania species and the sandfly vector involved in VL transmission in this area remain to be identified. Furthermore, the extent to which the geographical occurrence of both CL and VL is limited by the distributions of the parasite and the vector in Sri Lanka is unknown. However, because no cases of VL have been reported to date in our CL-endemic study locations in Matale (MHNSL 2009), epidemiological and entomological studies in the study area would help identify putative candidate vector sandfly species that might transmit both VL and CL or only CL.

Anthropophagous $P$. argentipes s.l. sandflies were reported by Lane et al. (1990) in the district of Kandy, which borders the south of Matale. More recently, among 13 locations selected across different climatic zones in an entomological survey conducted in 2005, P. argentipes s.l. was found to be widely distributed throughout the island and to be the predominant (44\% of the 584 sandfly collection) species. In addition, P. argentipes s.l. was found in $98-100 \%$ of the collections from each of the four Matale locations included in this survey (Ozbel et al. 2011). At one of these locations, Thalagoda, where Sergentomyia sp. was $2 \%$ of the sampled sandfly species in July 2005, further sampling in February 2006 revealed $70 \%$ Sergentomyia $\mathrm{sp}$. and only $30 \%$ P. argentipes s.l., indicating possible seasonal (Ozbel et al. 2011) sandfly population fluctuations, as reported by Surendran et al. (2007). In our study, only one out of 96 sandflies sampled in May 2008 was identified as Sergentomyia sp. and P. stantoni was not detected. The remaining 95 studied sandflies were identified as $P$. argentipes s.l. and their taxonomic classification within one of the recently described sibling populations was further examined (IIango 2010, Gajapathy et al. 2011).

The $P$. argentipes s.l. sandflies collected in this study had longer ascoids on flagellomere A2 and shallower pharyngeal armatures than any of the three documented $P$. argentipes s.l. siblings. These morphological differences, together with other significant morphometric differences identified in this study, suggest the existence of a new sibling population belonging to $P$. argentipes in areas of active transmission of cutaneous leishmaniasis. The wing venation pattern for these sandflies was not consistent with that of P. marginatus, a species considered synonymous, but reportedly differing from $P$. argentipes in colour pattern and wing index, and whose description was based on a now apparently lost single female specimen from Peradineya, located on the southern border of the present study area (Annandale 1910, Brunetti 1912, Ilango 2010).

Four variance components were extracted by PCA from the morphological data collected from members of the $P$. argentipes s.l. complex. Plotting the first two components against one another produced distinct clusters for each of the four sibling populations, indicating the existence of underlying morphological similarities between members of the same group. Although flies collected from Matale were separated from P. argentipes s.s. and $P$. annandale $i$, there was overlap between the values for $P$. glaucus and the flies examined in this study. The examination of larger number of flies is required to unambiguously establish whether the population described herein shows greater overall similarity to $P$. glaucus than to other members of the $P$. argentipes species complex. $P$. argentipes s.s., the known vector for VL in India, was found in sympatry with $P$. glaucus, although the latter has not been reported to act as a vector of VL to date (Ilango et al. 1994, Ilango 2010). The recent report of argentipes siblings in sympatry at three study sites in northern Sri Lanka (Gajapathy et al. 2011) and our own results further highlight the importance of investigating the presence of other $P$. argentipes s.l. siblings in Sri Lanka.

This current study documented the existence of a potentially new sibling population of the $P$. argentipes s.l. species complex near active CL foci in central Sri Lanka. The newly identified $P$. argentipes sibling population is suggested to be a putative vector of CL in central Sri Lanka and would increase the complexity of the $P$. argentipes s.l. population structure. Furthermore, it is now recognised that many insect vectors display complex population sub-structures (Conn \& Mirabello 2007).

Further research on the taxonomic status of $P$. argentipes is needed through cross-mating, behavioural and population genetics studies using molecular markers. It is also be important to estimate natural infection rates and the relative vector capacities of the different $P$. argentipes sibling species. Such studies would help to improve our understanding of the epidemiology of leishmaniasis, which is considered a newly emerged vectorborne disease in Sri Lanka.

\section{ACKNOWLEDGEMENTS}

To WHO, for funding a local training programme conducted by Prof Chamnan Apiwathnasorn on sandfly taxonomy where PHKIS Ranasinghe was a trainee, to the GIS branch, Department of Survey of Sri Lanka, for preparing the area map and providing other geographic data, to the Department of Meteorology of Sri Lanka, for providing climatic data, to Mr KA Sirisena, Divisional Secretary Naula, for providing the distances to patients' locations, to the Regional Malaria Officer Matale, for training the Technical Assistant in collecting the sandflies from the field, and to anonymous reviewers, for their helpful suggestions for improving this report.

\section{REFERENCES}

Abeygunasekara PH, Costa YJ, Seneviratne N, Ratnatunga N, Wijesundera $\mathrm{M}$ de $\mathrm{S}$ 2007. Locally acquired visceral leishmaniasis in Sri Lanka. Ceylon Med J 52: 30-31.

Annandale N 1910. Sandflies (Phlebotomus) from Peradeniya. Spolia Zeylanica 7: 57-62.

Athukorale DN, Seneviratne JK, Ihalamulla RL, Premaratne UN 1992. Locally acquired cutaneous leishmaniasis in Sri Lanka. J Trop Med Hyg 95: 432-433. 
Brunetti E 1912. Family: Psychodidae (Diptera: Nematocera). In Fauna of British India, Taylor \& Francis, London, p. 192-265.

Carter HF, Antonipulle P 1949. Observations on sandflies (Phlebotomus) in Delft Island, north Ceylon. Ann Trop Med Parasitol 43: $62-73$.

Conn JE, Mirabello L 2007. The biogeography and population genetics of neotropical vector species. Heredity 99: 245-256.

Daly HV 1985. Insect morphometrics. Ann Rev Entomol 30: 415-438.

Elamin EM, Guizani I, Guerbouj S, Gramiccia M, El-Hassan AM, Di Muccio T, Taha MA, Mukhtar MM 2008. Identification of Leishmania donovani as a cause of cutaneous leishmaniasis in Sudan. Trans R Soc Trop Med Hyg 102: 54-57.

El-Hossary S 2006. Morphological characteristics for sandfly taxonomy [manual on the Internet]. Research and Training Center on Vectors of Diseases, Ain Shams University, Cairo, Egypt. [cited 2009 Feb 25]. Available from: afpmb.org/bulletin/vol26/181282.pdf.

Gajapathy K, Jude PJ, Surendran SN 2011. Morphometric and meristic characterization of Phlebotomus argentipes species complex in northern Sri Lanka: evidence for the presence of potential leishmaniasis vectors in the country. Trop Biomed 28: 259-268.

Ilango K 2000. Morphological characteristics of the antennal flagellum and its sensilla chaeticum with character displacement in the sandfly Phlebotomus argentipes Annandale and Brunetti sensu lato (Diptera: Psychodidae). J Biosci 25: 163-172.

Ilango K 2010. A taxonomic reassessment of the Phlebotomus argentipes species complex (Diptera: Psychodidae: Phlebotominae). J Med Entomol 47: 1-15.

Ilango K, Dhanda V, Srinivasan R, Sadanand AV, Lane RP 1994. Phlebotomine sandflies (Diptera: Psychodidae) of Tamil Nadu and Pondicherry, southern India, in relation to visceral leishmaniasis. Ann Trop Med Parasitol 88: 413-431.

Karunaweera ND 2009. Leishmania donovani causing cutaneous leishmaniasis in Sri Lanka: a wolf in sheep's clothing? Trends Parasitol 25: 458-463.

Karunaweera ND, Pratlong F, Siriwardana HV, Ihalamulla RL, Dedet JP 2003. Sri Lankan cutaneous leishmaniasis is caused by Leishmania donovani zymodeme MON-37. Trans $R$ Soc Trop Med Hyg 97: 380-381.

Karunaweera ND, Rajapaksa US 2009. Is leishmaniasis in Sri Lanka benign and be ignored? J Vector Borne Dis 46: 13-17.

Lane RP, Pile MM, Amerasinghe FP 1990. Anthropophagy and aggregation behaviour of the sandfly Phlebotomus argentipes in Sri Lanka. Med Vet Entomol 4: 79-88.

Lane RP, Rahman SJ 1980. Variation in the ascoids of the sandfly Phlebotomus argentipes in population from Patna, northern India. J Commun Dis 124: 211-218.

Lewis DJ 1978. The phlebotomine sandflies (Diptera: Psychodidae) of the oriental region. Bull Br Mus (Nat Hist) Entomol 37: 217-343.

Lewis DJ, Killick-Kendrick R 1973. Some phlebotomid sandflies and other Diptera of Malaysia and Sri Lanka. Trans $R$ Soc Trop Med Hyg 67: 4-5.

MHNSL - Ministry of Healthcare and Nutrition Sri Lanka 2009. [homepage on the Internet]. Colombo: Epidemiology unit, Weekly Epidemiology Reports, Newly introduced notifiable disease,
Vol. 36 [last update 2010 date not available cited 2010 Dec 3]. Available from: epid.gov.lk/wer.htm.

MHNSL - Ministry of Healthcare and Nutrition Sri Lanka 2010. [homepage on the Internet]. Colombo: Epidemiology unit, Weekly Epidemiology Reports, Newly introduced notifiable disease, Vol. 37 [last update 2010 date not available cited 2010 Dec 3]. Available from: epid.gov.lk/wer.htm.

Murray HW, Berman JD, Davies CR, Saravia NG 2005. Advances in leishmaniasis. Lancet 366: 1561-1577.

Nawaratna SS, Weilgama DJ, Rajapaksha K 2009. Cutaneous leishmaniasis in Sri Lanka: a study of possible animal reservoirs. Int J Infect Dis 13: 513-517.

Nawaratna SS, Weilgama DJ, Wijekoon CJ, Dissanayake M, Rajapaksha K 2007. Cutaneous leishmaniasis, Sri Lanka. Emerg Infect Dis 13: 1068-1070.

Ozbel Y, Sanjoba C, Alten B, Asada M, Depaquit J, Matsumoto Y, Demir S, Siyambalagoda RR, Rajapakse RP, Matsumoto Y 2011. Distribution and ecological aspects of sandfly (Diptera: Psychodidae) species in Sri Lanka. J Vector Ecol 36: 77-86.

Rajapaksa US, Ihalamulla RL, Karunaweera ND 2005. First report of mucosal tissue localisation of leishmaniasis in Sri Lanka. Ceylon Med J 50: 90-91.

Rosypal AC, Tripp S, Kinlaw C, Hailemariam S, Tidwell RR, Lindsay DS, Rajapakse RP, Sreekumar C, Dubey JP 2010. Surveillance for antibodies to Leishmania spp in dogs from Sri Lanka. J Parasitol 96: 230-231.

Samaranayake TN, Dissanayake VH, Fernando SD 2008. Clinical manifestations of cutaneous leishmaniasis in Sri Lanka - possible evidence for genetic susceptibility among the Sinhalese. Ann Trop Med Parasitol 102: 383-390.

Siriwardana HV, Noyes HA, Beeching NJ, Chance ML, Karunaweera ND, Bates PA 2007. Leishmania donovani and cutaneous leishmaniasis, Sri Lanka. Emerg Infect Dis 13: 476-478.

Siriwardana HV, Thalagala N, Karunaweera ND 2010. Clinical and epidemiological studies on the cutaneous leishmaniasis caused by Leishmania (Leishmania) donovani in Sri Lanka. Ann Trop Med Parasitol 104: 213-223.

Surendran SN, Kajatheepan A, Hawkes NJ, Ramasamy R 2005. First report on the presence of morphospecies A and B of Phlebotomus argentipes sensu lato (Diptera: Psychodidae) in Sri Lanka - implications for leishmaniasis transmission. $J$ Vector Borne Dis 42: 155-158.

Surendran SN, Kajatheepan A, Ramasamy R 2007. Socio-environmental factors and sandfly prevalence in Delft Island, Sri Lanka: implications for leishmaniasis vector control. J Vector Borne Dis 44: 65-68.

Tabachnick BG, Fidel L S 2001. Using multivariate statistics, 4th ed., Allyn \& Bacon, Boston, 996 pp.

WHO - World Health Organization 1992. Part II tutor's guide. In Entomological field techniques for malaria control, WHO, Geneva, p. 55-58.

WHO - World Health Organization 2010. [homepage on the Internet]. Leishmaniasis background information. [last update 2010 date not available cited $2010 \mathrm{Jul}$ 25]. Available from: who.int/ leishmaniasis/en/. 


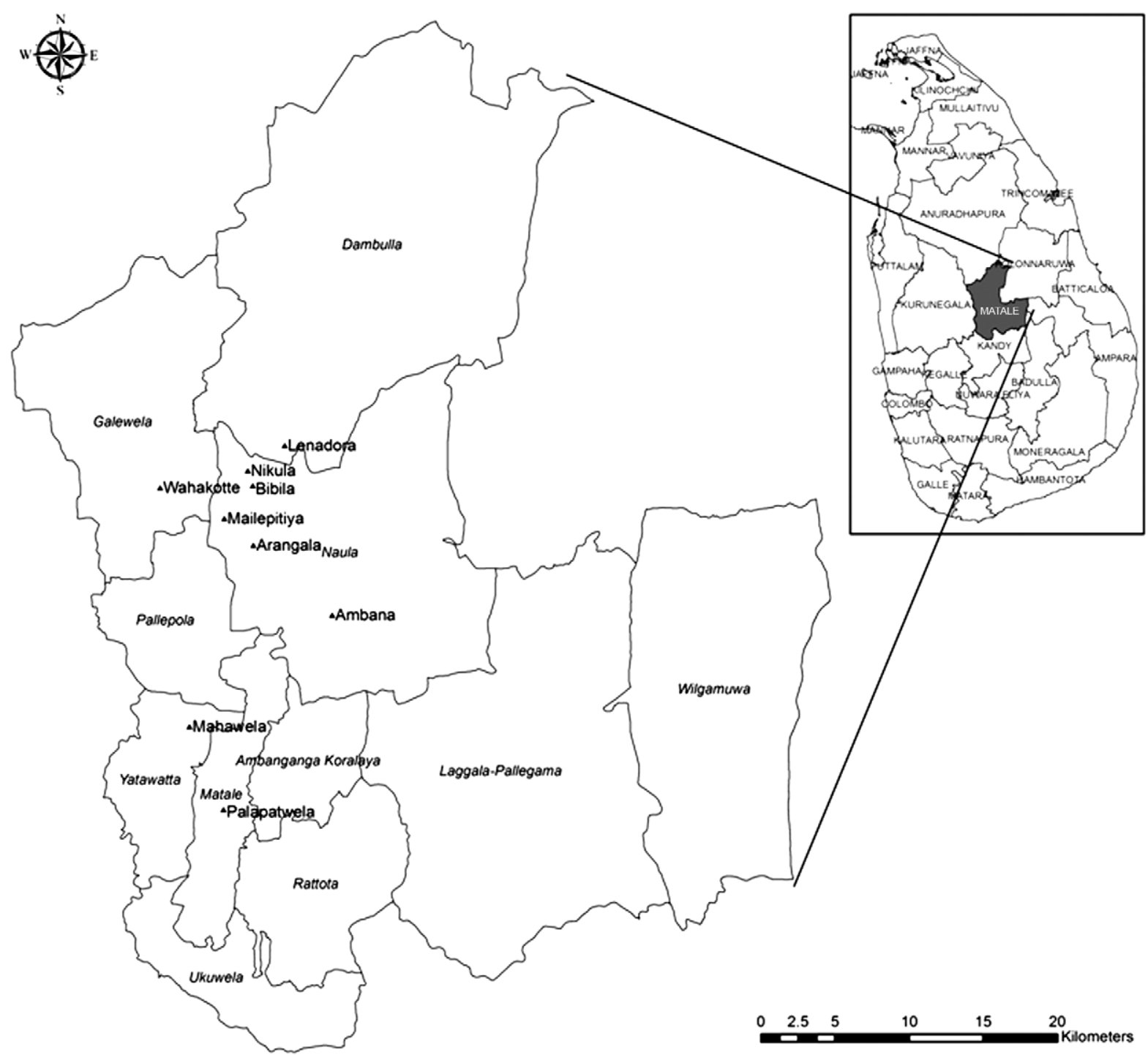

Fig. 1: study area. Area map of patient locations in the district of Matale, central Sri Lanka (prepared according to the geographic scale from a 1:50.000 map). 